10. Heyndrickx GR, Millard RW, McRitchie RJ, Maroko PR, Vatner SF. Regional myocardial function and electrophysiological alterations after brief coronary artery occlusion in conscious dogs. J Clin Invest 1975;56:978.

11. Theroux P, Ross J, Franklin D, Kemper W, Sasayama S. Coronary arterial reperfusion. III. Early and late effects on regional myocardial infarction and dimensions in conscious dogs. Am J Cardiol 1976;38:599.

12. DeBoer LWV, Ingwall JS, Kloner RA, Braunwald E. Prolonged derangements of canine myocardial purine metabolism after a brief coronary artery occlusion not associated with anatomic evidence of necrosis. Proc Natl Acad Sci $1980 ; 77: 5471$
13. Kloner RA, Ganote CE, Whalen DA, Jennings RB. Effect of a transient period of ischemia on myocardial cells. II. Fine structure during the first few minutes of reflow. Am J Pathol 1974;74:399.

14. Kloner RA, Rude RE, Carlson N, Maroko PR, DeBoer LWV, Braunwald E. Ultrastructural evidence of microvascular damage and myocardial cell injury after coronary artery occlusion: which comes first? Circulation 1980;62:945.

15. Braunwald E, Kloner RA. The stunned myocardium: prolonged, postischemic ventricular dysfunction. Circulation 1982;66:1146.

\title{
Prostacyclin protects ischemic reperfused myocardium in the dog by inhibition of neutrophil activation
}

\begin{abstract}
Prostacyclin $\left(\mathrm{PGL}_{2}\right)$ and the stable $\mathrm{PGl}_{2}$ analogue SC39902 $(6,9 \alpha$-epoxy,5S-fluoro-11 $\alpha, 15 S-$ dehydroxyproste-6,13E-dlen-1-olc acld, sodium salt) were studled in anesthetized open-chest dogs subjected to 90 minutes of left circumflex coronary artery (LCCA) occlusion and 6 hours of reperfusion. $\mathrm{PGI}_{2}(50 \mathrm{ng} / \mathrm{kg} / \mathrm{min}$, Infused into the left atrium) reduced infarct mass by $59 \%$ compared to control, but $8.039902(1.5 \mu \mathrm{g} / \mathrm{kg} / \mathrm{min})$ failed to produce a significant reduction in Inferct slze. Both $\mathrm{PCl}_{2}$ and SC39902 reduced mean arterlal blood preseure, heart rate, and rate-preseure product to the same extent. Reglonal myocardial blood flow measured with radiolabelled tracer microspheres did not demonstrate an Increase in regional blood flow to the lschemic myocardium during the 90 minutes of LCCA occlusion in the $\mathrm{PGl}_{2}$ and control treatment groups. Canine noutrophils were isolated from whole blood and activated with opsonized zymosan. $\mathrm{PGI}_{2}$ produced a concentration-dependent inhibition of neutrophil activation as measured by superoxide production in vitro, whereas SC39902 falled to effectively inhlbit neutrophll activation. Neutrophil migration into Inflammatory skin lesions was effectively attenuated when doge were pretreated with $\mathrm{PGl}_{2}(50 \mathrm{ng} / \mathrm{kg} / \mathrm{min}$, intrevenously). Therefore, it is suggested that the cytoprotective effect of $\mathrm{PGI}_{2}$ during myocardial ischemia and reperfusion is related to an inhibition of neutrophil migration and the production of cytotoxic activated oxygen 8pecles. (AM HEART J 1987;113:129.)
\end{abstract}

Paul J. Simpson, B.S.," Stephanie E. Mitsos, Ph.D.,* Anthony Ventura,* Kim P. Gallagher, Ph.D.,** Joseph C. Fantone, M.D., ${ }^{* * *}$ Gerald D. Abrams, M.D., *** M. Anthony Schork, Ph.D., ${ }^{* * *}$ and Benedict R. Lucchesi, Ph.D., M.D.* Ann Arbor, Mich.

From the Departments of Pharmacology, ${ }^{*}$ Physiology, ${ }^{* *}$ Pathology, ${ }^{* * *}$ and Biostatistics, ${ }^{* * * *}$ The University of Michigan Medical School and The School of Public Health.

This study was supported by a grant from the National Institutes of Health, National Heart, Lung, and Blood Institute (No. HL-19782), and by a grant-in-aid from G. D. Searle \& Co.

Received for publication Jan. 13, 1986; accepted May 5, 1986.

Reprint requests: Benedict R. Lucchesi, Ph.D., M.D., Dept. of Pharmacology, 7423 Medical Science I, The University of Michigan. Ann Arbor, MI 48109 .
Prostacyclin (epoprostenol, $\mathrm{PGI}_{2}$ ) is the major active arachidonic acid metabolite produced by vascular endothelium. ${ }^{1,2}$ It is the most potent endogenous inhibitor of platelet aggregation yet described, ${ }^{1}$ and is a potent systemic vasodilator ${ }^{3}$ and coronary artery vasodilator. ${ }^{4}$ Prostacyclin has been demonstrated to be protective in a number of experimental models of myocardial ischemia..$^{5-8}$ Lefer et al. ${ }^{9}$ demonstrated 
the usefulness of $\mathrm{PGI}_{2}$ for the treatment of acute myocardial ischemia. This was besed on the ability of $\mathrm{PGI}_{2}$ to inhibit platelet aggregation and favorably alter myocardial oxygen supply and demand by increasing coronary artery blood flow and reducing systemic blood pressure, respectively. Melin and Becker $^{10}$ demonstrated that $\mathrm{PGI}_{2}$ protects in the absence of an increase in collateral blood flow to the ischemic myocardium.

Recent studies ${ }^{11-13}$ have provided substantial evidence to demonstrate that polymorphonuclear leukocyte (neutrophil) infiltration during an evolving myocardial infarct contributes to irreversible myocardial tissue injury. Since prostacyclin inhibits in vitro production of cytotoxic oxygen-free radicals and release of degradative lysosomal enzymes, ${ }^{14-16}$ we hypothesize that the cytoprotective effect of $\mathrm{PGI}_{2}$ in canine regional myocardial ischemia and reperfusion is at least partly due to inhibition of neutrophil activation.

The purpose of this investigation was to determine the effectiveness of $\mathrm{PGI}_{2}$ and the chemically stable mono-fluorinated PGI $_{2}$ analogue (SC39902; $6,9 \alpha$-epoxy,5S-fluoro- $11 \alpha, 15 \mathrm{~S}$-dehydroxy-prosta6,13E-dien-1-oic acid, sodium salt) for reducing the extent of irreversibly injured myocardial tissue that results after 90 minutes of regional ischemia and 6 hours of reperfusion. We report on the effects of $\mathrm{PGI}_{2}$ and SC39902 on canine neutrophil activation by the particulate phagocytic stimulus, opsonized zymosan, as measured by superoxide anion production in vitro. Additionally, we report that $\mathrm{PGI}_{2}$ inhibits neutrophil migration in vivo into inflammatory skin sites at the same dose that reduces myocardial ischemia-reperfusion injury.

\section{METHODS}

Details of the methods have been published previously. ${ }^{12,17}$ Briefly, adult male mongrel dogs (12 to $17 \mathrm{~kg}$ ) were anesthetized with Dial-urethane $(0.6 \mathrm{ml} / \mathrm{kg})$ and ventilated with room air. The proximal left circumflex coronary artery (LCCA) was isolated and instrumented for continuous blood flow measurement with an electromagnetic flow probe. Heart rate, arterial blood pressure, LCCA blood flow, and ECG were continuously recorded. The three experimental groups in the study were: (1) Control (vehicle) $(\mathrm{n}=16), 50 \mathrm{mM}$ Tris-HCl, $\mathrm{pH} 9.4$ at $4^{\circ} \mathrm{C}$ in $0.9 \%$ saline; continuous infusion $(0.5 \mathrm{ml} / \mathrm{min})$ into the left atrium beginning 30 minutes before coronary artery occlusion, continuing during the 90 minutes of regional ischemia, and continuing during the first 2 hours of reperfusion. (2) Prostacyclin ( $\mathrm{n}=14$ ), $50 \mathrm{ng} / \mathrm{kg} / \mathrm{min}$ in the same vehicle, over the same time course as control. (3) SC39902 (G.D. Searle \& Co.) $(\mathrm{n}=10), 1.5 \mu \mathrm{g} / \mathrm{kg} / \mathrm{min}$ (same vehicle and time course).

Regional myocardial ischemia was produced by occlud- ing the LCCA for 90 minutes and then reperfusing through a critical stenosis ${ }^{18}$ for 6 hours. After 6 hours the infarct mass was assesed with the ex vivo dual perfusion technique previously described, ${ }^{12}$ in which the LCCA is perfused with $1.5 \%$ triphenyltetrazolium chloride in 50 mM potassium phosphate buffer ( $\mathrm{pH} 7.4$ at $37^{\circ} \mathrm{C}$ ) and the remainder of the coronaries are perfused with $0.25 \%$ Evan's blue dye. The hearts were then cut into five or six 1 cm thick transverse sections. Infarct size was then determined planimetrically.

Reglonal myocardial blood flow (RMBF). Radioactive microspheres (15 $\mu \mathrm{m}$ ) (New England Nuclear, North Billerica, Mass.) labelled with one of the following five isotopes- ${ }^{51} \mathrm{Cr},{ }^{141} \mathrm{Ce},{ }^{85} \mathrm{Sr},{ }^{103} \mathrm{Ru},{ }^{40} \mathrm{Sc}$-were used to assess regional myocardial blood flow, ${ }^{19}$ essentially as detailed previously. ${ }^{17}$ The times of microsphere injection were as follows: baseline (before drug or vehicle infusion), 25 minutes after drug or vehicle infusion, 10 minutes after LCCA occlusion, and 80 minutes after LCCA occlusion.

Tissue samples weighing 0.5 to $1.0 \mathrm{gm}$ were dissected from sections of the hearts after staining, from subepicardium, midmyocardium, and subendocardium from the LCCA perfusion region (which was rendered ischemic), and from the normally perfused nonischemic region. Three sections from each heart were used so that blood flows to each region represent the average of three samples for each experiment.

Histology. A midventricular transmural section of the area of the left ventricle supplied by the LCCA was examined by light microcopy in 21 hearts, seven from each of the three treatment groups (control, $\mathrm{PGI}_{2}, \mathrm{SC} 39902$ ). Paraffin-embedded tissue blocks were sectioned at 5 thickness and were stained with hematoxylin and eosin. The presence of necrosis was verified and the degree of hemorrhage was assessed by a pathologist (GDA) unaware of the experimental treatment groups.

Neutrophil preparation. Canine neutrophils were isolated from venous blood obtained from untreated dogs and were separated by Histopaque (Sigma Chemical Co., St. Louis, Mo.) gradient centrifugation followed by red blood cell lysis with a buffered ammonium chloride solution (150 $\mathrm{mM}\left[\mathrm{NH}_{4}\right]_{2} \mathrm{Cl}_{2} ; 10 \mathrm{mM} \mathrm{NaHCO} ; 1 \mathrm{mM}$ EDTA; $\mathrm{pH}$ 7.2). Cell viability was greater than $90 \%$ as determined by trypan blue exclusion. Cell preparations consisted of greater than $95 \%$ neutrophils. Superoxide $\left(\mathrm{O}_{2}^{-}\right)$production was measured by a modification of the method of Babior et al. ${ }^{20}$ as described by Fantone and Kinnes. ${ }^{14}$

Neutrophils $\left(5 \times 10^{6}\right.$ cells $\left./ \mathrm{ml}\right)$ were incubated at $37^{\circ} \mathrm{C}$ in the presence of $0.1 \mathrm{mM}$ ferricytochrome $\mathrm{C}$ in Hanks' balanced salt solution (HBSS) with $1 \mathrm{mg} / \mathrm{ml}$ glucose. The rate of superoxide production was determined as the superoxide dismutase (SOD) inhibitable (SOD $50 \mu \mathrm{g} / \mathrm{ml}$ in reference tubes) reduction of ferricytochrome $\mathrm{C}$ to ferrocytochrome $\mathrm{C}$ with the use of an extinction coefficient of $21.1 \mathrm{mM}^{-1} \mathrm{~cm}^{-1}$ at $550 \mathrm{mn}$. After an initial 3- minute incubation at $37^{\circ} \mathrm{C}$, Cytochalasin B $(5 \mu \mathrm{g} / \mathrm{ml})$ was added and 2 minutes later, opsonized zymosan (OZ) (10\% of final volume) was added to the neutrophils. $O Z$ was prepared by incubation of normal dog serum with zymo- 
Table 1. Hemodynamic measurements

\begin{tabular}{|c|c|c|c|c|}
\hline & & $\begin{array}{l}\text { Control } \\
(n=16)\end{array}$ & $\begin{array}{l}\text { Prostacyclin } \\
\quad(n=14)\end{array}$ & $\begin{array}{c}S C 39902 \\
(n=10)\end{array}$ \\
\hline \multirow[t]{4}{*}{ Heart rate $(\mathrm{bpm})$} & Baseline & $145 \pm 6$ & $124 \pm 5 \dagger$ & $138 \pm 8$ \\
\hline & Drug & $148 \pm 6$ & $119 \pm 5 \dagger$ & $130 \pm 9^{*}$ \\
\hline & Occlusion & $139 \pm 5$ & $124 \pm 5$ & $139 \pm 5$ \\
\hline & Reperfusion & $151 \pm 8$ & $148 \pm 8$ & $180 \pm 13$ \\
\hline \multirow[t]{4}{*}{ Mean arterial pressure $(\mathrm{mm} \mathrm{Hg})$} & Baseline & $119 \pm 4$ & $115 \pm 5$ & $119 \pm 6$ \\
\hline & Drug & $119 \pm 4$ & $88 \pm 5 \dagger$ & $101 \pm 5 \dagger$ \\
\hline & Occlusion & $93 \pm 4$ & $78 \pm 4^{*}$ & $90 \pm 3$ \\
\hline & Reperfusion & $91 \pm 4$ & $93 \pm 5$ & $102 \pm 5$ \\
\hline Rate-pressure product (mm & Baseline & $21.6 \pm 1.4$ & $18.1 \pm 1.2$ & $20.1 \pm 1.4$ \\
\hline \multirow[t]{3}{*}{$\mathrm{Hg} / \min \times 1000)$} & Drug & $22.7 \pm 1.6$ & $14.1 \pm 0.9 \dagger$ & $16.2 \pm 1.2 \dagger$ \\
\hline & Occlusion & $16.7 \pm 1.0$ & $13.5 \pm 1.0$ & $16.1 \pm 1.0$ \\
\hline & Reperfusion & $17.4 \pm 1.8$ & $18.5 \pm 1.4$ & $23.6 \pm 2.0$ \\
\hline
\end{tabular}

All values expressed as mean \pm standard error.

Baseline = before drug; Drug = 30 minutes after vehicle or drug infusion; Occlusion $=30$ minutes after LCCA occlusion; Reperfusion $=6$ hours after LCCA reperfusion.

${ }^{*} p<0.05,+p<0.01$, compared to control at same time point.

$\operatorname{san} \mathrm{A}$ (Sigma; $10 \mathrm{mg} / \mathrm{ml}$ ) for 30 minutes at $37^{\circ} \mathrm{C}$ and then by washing the zymosan twice with sterile normal saline. The $\mathrm{OZ}$ was then resuspended in normal saline to 10 $\mathrm{mg} / \mathrm{ml}$. Prostaglandins, when present, were serially diluted immediately before use in $\operatorname{HBSS}\left(4^{\circ} \mathrm{C}\right)$ and were added at the same time as the cells.

Evaluation of neutrophil migration in vivo. Seven dogs were anesthetized with Dial-urethane and (randomized into one of two treatment groups: (1) Prostacyclin, 50 $\mathrm{ng} / \mathrm{kg} / \mathrm{min}$ in vehicle $\left(50 \mathrm{mM}\right.$ Tris $\mathrm{HCl}$ buffer (pH 9.4 at $4^{\circ}$ C) in $0.9 \%$ saline) by intravenous infusion $0.5 \mathrm{ml} / \mathrm{min}$; or (2) Control (vehicle). The chest and back of each dog was carefully shaved and zymosan-activated dog plasma (ZAP) $(0.2 \mathrm{ml})$ was injected intradermally at random sites 30 minutes after the respective intravenous treatment had begun. ZAP was prepared by incubating normal dog plasma with zymosan $A(10 \mathrm{mg} / \mathrm{ml})$ for 30 minutes at $37^{\circ}$ $\mathrm{C}$ and then removing the zymosan by centrifugation. Biopsies (100 to $300 \mathrm{mg}$ each) were taken at $0,0.5,1.0$, and 2.0 hours after ZAP injection. The neutrophil-specific enzyme, myeloperoxidase ${ }^{21}$ was extracted and measured spectrophotometrically as detailed by Bradley et al. ${ }^{22}$ The myeloperoxidase content of tissue has been shown to be a good marker of skin neutrophil content. ${ }^{21,22}$

Statistical analyses. Hemodynamic data (heart rate, mean arterial pressure rate-pressure product, LCCA blood flow) and infarct sizes were analyzed with a one-way analysis of variance (ANOVA) at each time point where there were three groups (control, $\mathrm{PGI}_{2}$, and SC39902). The groups of data that were found to be significantly different from the ANOVA were analyzed further with Dunnett's test for multiple comparisons to control. ${ }^{23} p$ values less than 0.05 were considered significant. Regional myocardial blood flows (RMBFs) were analyzed with unpaired Student's $t$ tests for each comparison between the two treatment groups. Paired Student's $t$ tests were used to test for differences with time in the RMBF studies. ${ }^{24} \mathrm{~A}$ Bonferroni $\alpha$-error protection was used if any of these differences were found to be significant. In vitro superoxide production was analyzed by unpaired Student's $t$ test for each concentration of $\mathrm{PGI}_{2}$ or $\mathrm{SC} 39902$ compared to the superoxide production in the absence of either $\mathrm{PGI}_{2}$ or SC39902. Myeloperoxidase content of tissue samples were compared by Student's $t$ test.

\section{RESULTS}

Thirty-four dogs were assigned randomly to one of the three treatment groups (control, $\mathrm{PGI}_{2}$, or SC39902) for initial assessment of drug effect on resulting myocardial infarct size. Three dogs, one from each of the three treatment groups, were eliminated due to ventricular fibrillation during reperfusion which was not converted with fewer than four DC countershocks. Fourteen more dogs were randomized into one of two treatment groups (control or $\mathrm{PGI}_{2}$ ) for assessment of treatment effects on changes in RMBF. Of these 14 dogs, three control dogs and one $\mathrm{PGI}_{2}$-treated dog were eliminated from the study due to ventricular fibrillation. Two more dogs (one control, one $\mathrm{PGI}_{2}$ ) were eliminated from the study due to technical problems with microsphere injection and reference blood sample withdrawals.

Hemodynamic effects of $\mathrm{PGl}_{2}$ and sc30902. The doses of $\mathrm{PGI}_{2}(50 \mathrm{ng} / \mathrm{kg} / \mathrm{min})$ and $\mathrm{SC} 39902(1.5$ $\mu \mathrm{g} / \mathrm{kg} / \mathrm{min}$ ) were chosen on the basis of their ability to produce a similar decrease in blood pressure. Prostacyclin infusion resulted in a $23 \%$ reduction $(-27 \mathrm{~mm} \mathrm{Hg})$ in mean arterial blood pressure (MAP) (Table I) after 30 minutes of infusion, from 


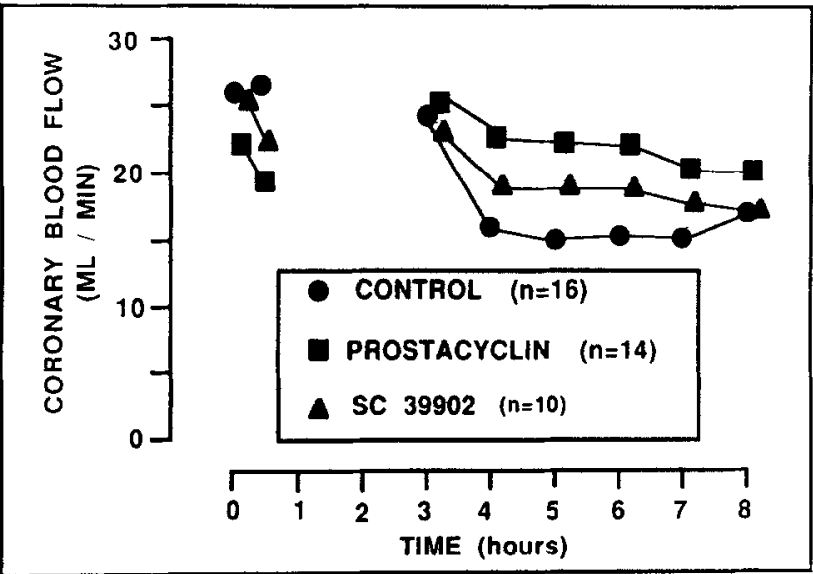

Fig. 1. Left circumflex coronary artery (LCCA) blood flow at regular intervals during the experiments. Drug or vehicle infusion was begun after recording 0 hour flows and was continued until 2 hours after reperfusion ( 4 hours). The LCCA was occluded for 90 minutes, beginning after 30 minutes of drug or vehicle infusion. There were no differences among treatment groups at any time point (ANOVA).

$115 \pm 5$ to $88 \pm 5 \mathrm{~mm} \mathrm{Hg}(\mathrm{n}=14)$. Similarly, infusion of SC39902 resulted in a reduction in MAP from $119 \pm 6$ to $101 \pm 5 \mathrm{~mm} \mathrm{Hg}(\mathrm{n}=10)$. Occlusion of the LCCA typically results in a decline in MAP, as demonstratd in Table I comparing control before occlusion $(119 \pm 4 \mathrm{~mm} \mathrm{Hg})$ to control at 30 minutes of regional myocardial ischemia $(93 \pm 4 \mathrm{~mm} \mathrm{Hg})$. MAP was comparable after LCCA occlusion among all three treatment groups throughout the 6-hour reperfusion period.

Baseline heart rates (HR) (Table I) were slower in the $\mathrm{PGI}_{2}$-treated group $(p<0.05)$; however, after 30 minutes of $\mathrm{PGI}_{2}$ or SC39902 infusion, both $\mathrm{PGI}_{2}$ and SC39902 groups had significantly slower heart rates compared to control (both $p<0.05$ ). Heart rates were comparable among groups during the 90-minute ischemic period and throughout the 6hour reperfusion period.

Rate-pressure product (RPP) (systolic blood pressure $\times$ heart rate/1000) is used as an index of myocardial oxygen consumption. ${ }^{25}$ RPP was monitored throughout the experiments to determine whether changes in oxygen demand due to treatment could be responsible for any protective effect on the resulting myocardial infarct size. Baseline mean values for RPP did not differ among the three treatment groups (Table I) (Control: $21.6 \pm 1.4 \mathrm{~mm}$ $\mathrm{Hg} / \mathrm{min} / 1000 ; \mathrm{PGI}_{2} ; 18.1 \pm 1.2 \mathrm{~mm} \mathrm{Hg} / \mathrm{min} / 1000$; SC39902: $20.1 \pm 1.4 \mathrm{~mm} \mathrm{Hg} / \mathrm{min} / 1000$ ). However, after 30 minutes of infusion of $\mathrm{PGI}_{2}$ or $\mathrm{SC} 39902$, rate-pressure product was significantly reduced in both $\mathrm{PGI}_{2}$ and SC39902 treatment groups compared to control $(p<0.01)$. Upon LCCA occlusion, this index was similar among groups and remained so throughout the 6-hour reperfusion period.

Mean LCCA blood flows were comparable before treatment (Fig. 1). After 30 minutes of infusion of $\mathrm{PGI}_{2}$ or SC39902, LCCA coronary blood flows were similar when compared to the vehicle control group (control $=27 \pm 3 \mathrm{ml} / \mathrm{min}, \mathrm{n}=16 ; \mathrm{PGI}_{2}=19 \pm 2$ $\mathrm{ml} / \mathrm{min}, \mathrm{n}=14 ; \mathrm{SC} 39902=22 \pm 4 \mathrm{ml} / \mathrm{min}, \mathrm{n}=10$; $\mathrm{PGI}_{2}$ both $p>0.05$ compared to control). After 90 minutes of complete LCCA occlusion, blood flow was resumed slowly over 15 minutes. All mean LCCA blood flows were comparable among groups at every time point observed subsequent to reperfusion.

Effects of $\mathrm{PGl}_{2}$ and SC39902 on infarct size. The effects of $\mathrm{PGI}_{2}$ and $\mathrm{SC} 39902$ on resulting myocardial injury due to ischemia and reperfusion are depicted in Fig. 2. The ratios of the amount of left ventricle rendered ischemic (AREA AT RISK [AR]) to the total left ventricle (LV) were equivalent among the three treatment groups (control: $n=13, \quad A R$ / $\mathrm{LV}=45.5 \pm 1.7 \%, \mathrm{PGI}_{2}: \mathrm{n}=12, \mathrm{AR} / \mathrm{LV}=40.3 \pm$ $2.4 \%$; SC39902: $\mathrm{n}=10, \quad \mathrm{AR} / \mathrm{LV}=48.9 \pm 2.1 \%$; $p>0.05$ by ANOVA). Infarct size was reduced significantly with $\mathrm{PGI}_{2}$ treatment $(p<0.001$ by ANOVA and Dunnett's, control vs $\mathrm{PGI}_{2}$ ) when expressed as a percentage of $\mathrm{LV}$ or as a percentage of the area at risk. On the other hand, SC39902 demonstrated a hemodynamic profile (HR, MAP, RPP, LCCA blood flow) similar to that with $\mathrm{PGI}_{2}$ but failed to significantly alter the size of the myocardial infarct that evolved after 90 minutes of regional ischemia and 6 hours of reperfusion. Infarcts expressed as a percentage of the area of myocardium at risk were as follows: control: $n=13,47.4 \pm 4.7 \%$; $\mathrm{PGI}_{2}: \mathrm{n}=12$, $19.2 \pm 2.0 \% ; \quad$ SC39902: $\mathrm{n}=10, \quad 36.5 \pm 5.5 \%$; ( $p<0.001$ Dunnett's, control compared to $\mathrm{PGI}_{2}$ ).

Regional myocardial blood flows were determined at four time points during the experiments (Fig. 3). The purpose of measuring RMBF is to determine whether the protective effect of $\mathrm{PGI}_{2}$ on the evolving mass of myocardial infarct is due to alteration of regional blood flow distribution. LCCA occlusion resulted in a significant decline in myocardial blood flow in all three myocardial regions (subepicardial, midmyocardial, and subendocardial) and to a similar extent in both control and the $\mathrm{PGI}_{2}$ treatment groups. Endocardial blood flow was reduced by $91 \%$ and $93 \%$ in control and prostacyclin treated groups, respectively; midmyocardial flow declined by $84 \%$ (control) and 91\% (PGI $)$; and epicardial flows declined by $67 \%$ (control) and $85 \%\left(\mathrm{PGI}_{2}\right)$. Blood flows in each of the three regions were not increased 


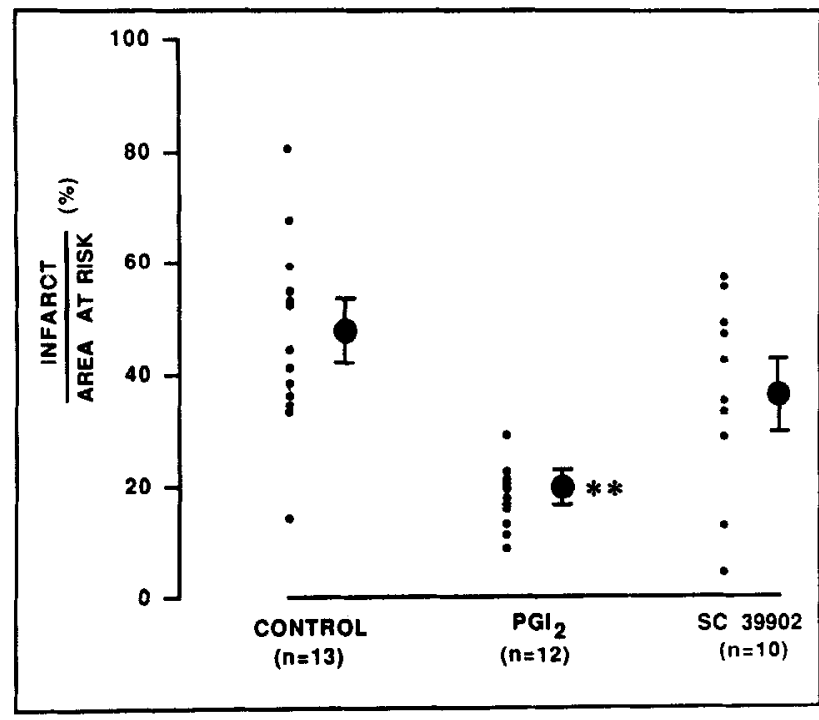

Fig. 2. Myocardial infarct size was measured after 6 hours of reperfusion. Mean infarct mass is expressed as a percentage of the area of the myocardium at risk of infarction, depicted as individual points for each experiment along with the mean \pm standard error of the mean for each treatment group. $\mathrm{PGI}_{2}$ treated dogs developed a significantly smaller infarct compared to controls ( ${ }^{* *} p<0.01$, ANOVA, Dunnett's).

during LCCA occlusion in the ischemic perfusion bed when early (10 minutes after occlusion) and late occlusion ( 80 minutes after occlusion) flows were compared (paired $t$ test). Therefore, there was no significant increase in collateral flow that could account for the protective effect of $\mathrm{PGI}_{2}$ on the evolving infarct mass. Endocardial/epicardial blood flow ratios were calculated to determine if the blood was being redistributed within the myocardium. Endocardial/epicardial flow ratios remained unchanged with treatment (control pretreatment $1.38 \pm 0.07 \mathrm{ml} / \mathrm{min} / \mathrm{gm}$, after vehicle $1.38 \pm 0.08$ $\mathrm{ml} / \mathrm{min} / \mathrm{gm} ; \mathrm{PGI}_{2}$ pretreatment $1.17 \pm 0.03 \mathrm{ml} / \mathrm{min} /$ $\mathrm{gm}$, after $\mathrm{PGI}_{2} 1.08 \pm 0.09 \mathrm{ml} / \mathrm{min} / \mathrm{gm}$ ) in the region of the myocardium perfused by the LCCA. The endocardial/epicardial ratios during occlusion within the ischemic area were $0.4 \pm 0.11$ for the $\mathrm{PGI}_{2}$ group and $0.15 \pm 0.40$ for the control group $(p>0.05)$. This again confirms that the protective effect of $\mathrm{PGI}_{2}$ on infarct size is independent of blood flow redistribution. Blood flows in the area of the heart not rendered ischemic are depicted on the right side of Fig. 3. As is evident from the figure, there were no significant differences in blood flows in this region with time (paired $t$ test) or between groups (control, $\mathrm{PGI}_{2}$ ) at any time tested (unpaired $t$ test). Endocardial/epicardial flow ratios in the nonischemic regions were similar to endocardial/epicardial ratios obtained in the region perfused by the LCCA.

\section{REGIONAL MYOCARDIAL BLOOD FLOWS}

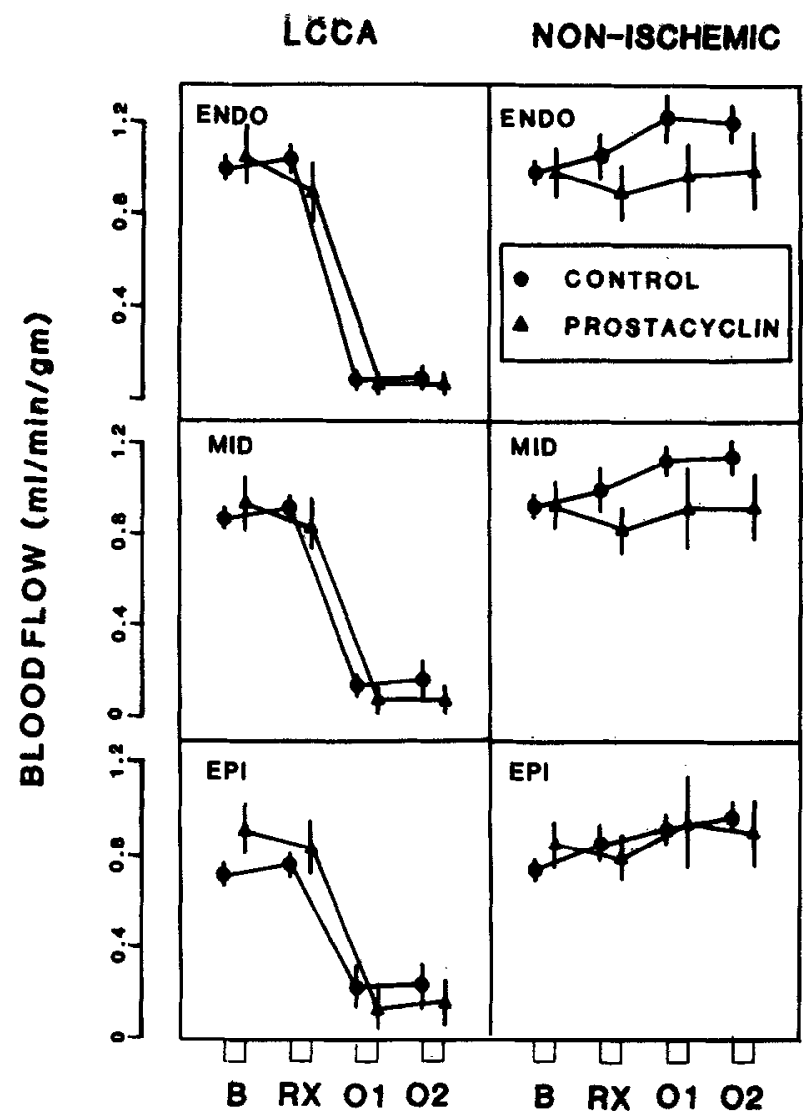

Fig. 3. Regional myocardial blood flow to the region of the heart that is rendered ischemic is depicted on the left half of the figure. On the right is the nonischemic region. Subendocardial (ENDO) blood flow is depicted in the top two panels, midmyocardial (MID) flow is shown in the middle two panels, and subepicardial (EPI) flow is illustrated in the bottom two panels. Baseline $(B)$ blood flow represents before $\mathrm{PGI}_{2}$ or vehicle infusion. $R X$ represents 25 minutes after $P \mathrm{I}_{2}$ or vehicle infusion. 01 and 02 represent 10 and 80 minutes, respectively, after LCCA occlusion. There were no significant differences between groups (Student's $t$ test) in any region or at any time point (Control $=$ filled circles; $\mathrm{PGI}_{2}=$ filled triangles).

Histology. Representative transmural sections from each of 21 hearts were used to assess relative degree of ischemic injury by light microscopy. Tissue samples were prepared for histologic examination such that regions from the central infarct area, the border region between normal tissue and necrotic tissue, and the normal tissue were analyzed. No significant differences were observed among the three treatment groups (control, PGI, SC39902) with respect to the appearance of the necrotic tissue in the central infarct area. No differences among treatment groups were discernible with respect to the extent of hemorrhage in the infarct area or 


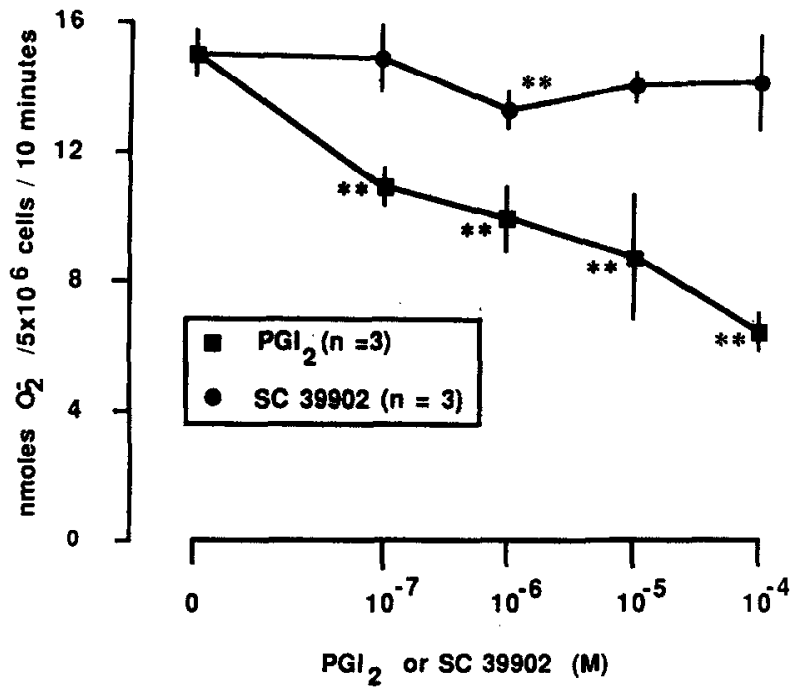

Fig. 4. Inhibition of superoxide generation by $\mathrm{PGI}_{2}$ but not by SC39902. Canine neutrophils were activated with opsonized zymosan. $\mathbf{P G I}_{2}$ produced a concentration-dependent inhibition of $\mathrm{O}_{2}-$ generation while SC39902 weakly inhibited only at $10^{-6} \mathrm{M}$. Each symbol represents the mean \pm S.E.M. of three determinations except that $n=6$ for $0 \quad \mathrm{PGI}_{2}$ or SC39902. PGI ${ }_{2}$ or $\mathrm{SC} 39902$ were serially diluted in cold Hank's buffer immediately before addition to the tubes. ${ }^{* *} p<0.001$ compared to $\mathrm{O}_{2}^{-}$in the absence of $\mathrm{PGI}_{2}$ or SC39902.

border regions. Gross inspection of histologic sections revealed no discernible differences in relative neutrophil content in infarcted tissue or border regions.

Frequency of ventricular fibrillation. The development of spontaneous ventricular fibrillation (VF) was monitored in this study to determine whether $\mathrm{PGI}_{2}$ or SC39902 may affect the frequency of VF. Previous reports suggest that $\mathrm{PGI}_{2}$ and $\mathrm{PGI}_{2}$ analogues may be either antiarrhythmic or arrhythmogenic, depending on the dose of drug used. ${ }^{26,27}$ The overall incidence of VF was 7 of 48 dogs in the study with control frequency of 4 of 19 , for $\mathrm{PGI}_{2}$ it was 2 of 18 dogs, and for SC39902 it was 1 of 11 dogs (chi square $=1.166, p>0.05$ ). Therefore was no difference in the relative frequency of observed in this study.

In vitro superoxide production by canlne neutrophlle. Canine neutrophils were stimulated with $O Z$ and superoxide $\mathrm{O}_{2}^{-}$generation was monitored spectrophotometrically (at $550 \mathrm{mn}$ ) by the superoxide dismutase inhibitable reduction of ferricytochrome C. Fig. 4 demonstrates that prostacyclin produces a concentration-dependent inhibition of neutrophil activation. The rate of superoxide production in the absence of $\mathrm{PGI}_{2}$ or $\mathrm{SC} 39902$ was $15.23 \pm 0.22$

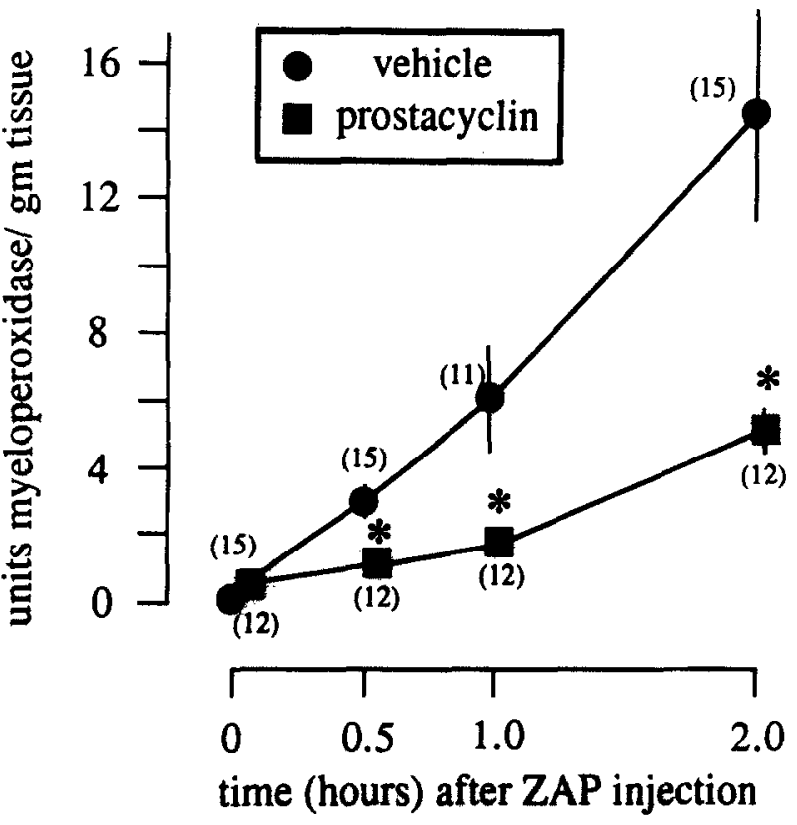

Fig. 5. Inhibition of neutrophil migration into inflammatory skin lesions. The number of individual biopsies is in parentheses. Vertical lines represent the standard error of the mean $\left({ }^{* *} p<0.01\right.$, Student's $t$ test). The symbols represent the mean of four vehicle treated and $3 \mathrm{PGI}_{2}$ treated dogs. $\mathrm{PGI}_{2}$ dose was $50 \mathrm{ng} / \mathrm{kg} / \mathrm{min}$ intravenously.

nmoles $\mathrm{O}_{2}=/ 5 \times 10^{6}$ cells $/ 10$ minutes. $\mathrm{PGI}_{2}$ at a concentration of $10^{-7} \mathrm{M}$ inhibited $\mathrm{O}_{2}-$ production by $27 \%$ compared to control (no PG). At a $\mathrm{PGI}_{2}$ concentration of $10^{-4} \mathrm{M}$, superoxide production was inhibited by $55 \%$ compared to control. In contrast, SC39902 did not show a concentration-dependent inhibition of superoxide production. Moreover, SC39902 at a concentration of $10^{-6} \mathrm{M}$ was the only concentration that was found to be significantly different from control. At this concentration, SC39902 inhibition was only $11 \%$ compared to control.

Neutrophil migration into dermal inflammatory lesions. Fig. 5 shows that prostacyclin at $50 \mathrm{ng} / \mathrm{kg} / \mathrm{min}$ effectively inhibits neutrophil migration into skin lesions induced by activated complement fragments (primarily C5a desArg). The myeloperoxidase content at the time of zymosan-activated plasma (ZAP) injection was $0.41 \pm 0.08 \mathrm{U} / \mathrm{gm}$ in the vehicle treated group and $0.54 \pm 0.24 \mathrm{U} / \mathrm{gm}$ in the $\mathrm{PGI}_{2}$ treated group $(p>0.05)$. The myeloperoxidase content of skin lesions was significantly less at $0.5,1.0$ and 2.0 hours after ZAP injection (all $p<0.01$ compared to control). Furthermore, neutrophilic infiltration in the $\mathrm{PGI}_{2}$ treated dogs was only $36.3 \%$ of the control value at the 2 hour time point $(14.68 \pm 3.01 \mathrm{U} / \mathrm{gm}$ vs $5.33 \pm 0.65$ $\mathrm{U} / \mathrm{gm})$. 


\section{DISCUSSION}

A number of investigators have attempted to define the relevant mechanism for the myocardial protection by prostacyclin in the setting of experimental myocardial ischemia. ${ }^{6 \cdot 10,28,29}$ The reduction of arterial blood pressure by $\mathrm{PGI}_{2}$ would at least theoretically reduce myocardial ischemia by reducing afterload and thus myocardial oxygen demand. ${ }^{30,}{ }^{31}$ In the present study, myocardial oxygen consumption as estimated by the rate-pressure product ${ }^{25}$ was reduced to the same extent by $\mathrm{PGI}_{2}$ and SC39902 (Table I). Prostacyclin resulted in a $59 \%$ reduction in infarct size with respect to the area at risk compared to controls, whereas SC39902 failed to reduce infarct size (Fig. 2). The relevant mechanism of protection by $\mathrm{PGI}_{2}$ is therefore not due to a reduction in myocardial oxygen demand.

Jugdutt et al. ${ }^{6}$ demonstrated that $\mathrm{PGI}_{2}$, by virtue of its vasodilatory properties, increased collateral blood flow to the ischemic myocardium in closed-chest conscious dogs subjected to permanent coronary artery occlusion. Indeed, in the aforementioned study, protection of the ischemic myocardium after permanent coronary artery occlusion is probably dependent upon the ability of $\mathrm{PGI}_{2}$ to increase collateral blood flow, since $P G E_{1}$ and $P G I_{2}$ reduced infarct size while $P G E_{2}$ did not. Prostaglandins $E_{1}$ and $I_{2}$ increased collateral blood flow in that study but $\mathrm{PGE}_{2}$ did not, while all three prostaglandins produced a similar reduction in blood pressure. In another study, Melin and Becker ${ }^{10}$ demonstrated that even in the absence of increased collateral blood flow to the ischemic myocardium, $\mathbf{P G I}_{2}$ treatment resulted in a reduction in myocardial necrosis. We report that $\mathrm{PGI}_{2}$ reduced infarct mass without increasing collateral blood flow to the ischemic myocardium during 90 minutes of regional ischemia. LCCA blood flow during reperfusion was similar among the three treatment groups (control, $\mathrm{PGI}_{2}, \mathrm{SC}_{39902}$; Fig. 1 ), suggesting that the mechanism of protection was independent of changes in blood flow to the previously ischemic myocardium and was not related to the "noreflow" phenomenon. ${ }^{32}$

We hereby offer an alternative explanation for the cytoprotective effect of $\mathbf{P G I}_{2}$ in ischemic myocardium in vivo. Prostacyclin can inhibit human neutrophil stimulation by formylmethionyl-leucyl-phenylalanine (fMet-Leu-Phe) and zymosan activated serum (complement activation products) as determined by superoxide production and lysosomal enzyme release in vitro. ${ }^{14-16}$ In addition, prostaglandins of the $\mathrm{E}$ series inhibit neutrophil chemotaxis, superoxide production, and degranulation in a variety of species, presumably through an increase in neutrophil intracellular concentration of cyclic adenosine monophosphate (AMP).${ }^{16}$ We report in this study that $\mathrm{PGI}_{2}$ can effectively inhibit canine neutrophil activation in vitro as measured by superoxide-specific reduction of ferricytochrome $\mathrm{C}$. The $\mathrm{PGI}_{2}$ analogue SC39902 manifests hemodynamic effects similar to those of $\mathrm{PGI}_{2}$ in vivo (i.e., reduces blood pressure) and also inhibits platelet aggregation in vitro (unpublished observations). A recent report ${ }^{33}$ demonstrated that SC39902 is an effective inhibitor of platelet activation in vivo as measured by the ability to prevent adenosine diphosphate (ADP)-induced thrombocytopenia in rats. Despite these similarities to $\mathrm{PGI}_{2}$, the analogue SC39902 failed to produce effective inhibition of canine neutrophil activation in vitro when stimulated with OZ. Furthermore, SC39902 does not protect the ischemic-reperfused myocardium with respect to ultimate infarct size. We propose, therefore, that the relevant mechanism for $\mathrm{PGI}_{2}$ protection in our experimental model is via the inhibition of neutrophil activation.

The concentration of $\mathrm{PGI}_{2}$ that produces $50 \%$ inhibition of neutrophil $\mathrm{O}_{2}^{-}$production is very similar to the $30 \mu \mathrm{M}$ of $\mathrm{PGI}_{2}$ for $50 \%$ inhibition reported by Fantone and Kinnes. ${ }^{14}$ The concentrations of $\mathrm{PGI}_{2}$ achieved in vivo with an infusion rate of $50 \mathrm{ng} / \mathrm{kg} / \mathrm{min}$ would be expected to approach the concentration range of $10^{-7}$ in vivo. Furthermore, inhibition of neutrophil migration in vivo by $\mathrm{PGI}_{2}(50 \mathrm{ng} / \mathrm{kg} / \mathrm{min})$ was demonstrated and is likely to be the relevant mechanism of protection of the ischemic reperfused myocardium.

The proinflammatory role of the neutrophil during myocardial ischemia and reperfusion injury has been demonstrated. ${ }^{11}$ Hill and Ward ${ }^{34}$ in 1971 demonstrated that complement is activated via the alternative pathway during myocardial ischemia. Maroko et al. ${ }^{35}$ depleted dogs of complement component 3 (C3) with cobra venom factor. Complement depletion resulted in reduced tissue damage and reduced neutrophil infiltration into the ischemic myocardium. Pinckard et al. ${ }^{36}$ extended these observations to the baboon, and demonstrated complement localization within the ischemic myocardium by direct immunofluorescence methods. Neutrophils, when activated by complement fragments, produce oxygen-derived free radicals and release degradative lysosomal enzymes, both of which are capable of mediating tissue destruction.

Using another approach, Romson et al. ${ }^{12}$ demonstrated a $44 \%$ reduction in the mass of myocardial infarct that evolved when dogs were made neutropenic before the induction of regional myocardial ischemia. In a related study, Romson et al. ${ }^{13}$ demonstrated that the protective effect of ibuprofen (a nonsteroidal antiinflammatory agent) upon the ischemic/reperfused myocardium was correlated with the ability of the drug 
to inhibit the infiltration of neutrophils into the ischemic myocardium. Kuehl et al. ${ }^{37}$ demonstrated that $\mathbf{P G I}_{2}$ inhibits neutrophil lipoxygenase activity. Neutrophil lipoxygenase products provide an important proinflammatory amplification signal. Leukotriene $B_{4}$, produced by neutrophils, is a potent chemoattractant for neutrophils, macrophages, and blood monocytes. Inhibition of lipoxygenase by $\mathrm{PGI}_{2}$ would therefore result in a reduction in phagocytic cell infiltration and thus reduce cellular necrosis.

In summary, we report the effectiveness of $\mathrm{PGI}_{2}$ for reducing myocardial infarct mass in the dog with temporary regional myocardial ischemia and reperfusion. The $\mathrm{PGI}_{2}$ analogue $\mathrm{SC} 39902$ produced a similar reduction in arterial blood pressure and heart rate but failed to reduce infarct mass. In vitro canine neutrophil activation was inhibited in a concentration-dependent manner by $\mathrm{PGI}_{2}$, whereas SC39902 failed to effectively inhibit neutrophil activation over the same concentration range. The data on neutrophil migration into inflammatory skin lesions demonstrate that neutrophil function is affected in vivo at the same dose of $\mathrm{PGI}_{2}$ that reduces myocardial ischemic reperfusion injury. These data suggest that the cytoprotective effect of $\mathrm{PGI}_{2}$ in this experimental model of myocardial infarction is due to inhibition of neutrophil activation.

The studies described in this report may have relevance with respect to the clinical management of patients who are evolving an acute myocardial infarction and who become candidates for thrombolytic therapy with streptokinase or perhaps tissue plasminogen activator. There are sufficient data to suggest that $\mathrm{PGI}_{2}$ is capable of preventing platelet aggregation ${ }^{2}$ and that the prostanoid may be of value as an adjunct to thrombolytic therapy, whereby it may serve to prevent reocclusion of the successfully recanalized coronary artery. ${ }^{38}$ The data presented in this report might give added importance for the concomitant use of PGI $_{2}$ along with thrombolytic therapy as an approach for the prevention of that component of myocardial injury associated with reperfusion of the ischemic heart. Furthermore, our data with respect to the cytoprotective effect of $\mathrm{PGI}_{2}$, while in agreement with that of previous investigators, ${ }^{5-10}$ provide an explanation for the mechanism by which $\mathrm{PGI}_{2}$ elicits its beneficial action through an inhibition of neutrophil function.

We wish to acknowledge the assistance of Dr. Marshal Shlafer with the neutrophil superoxide assays and that of Dr. Richard A. Gerren with the regional myocardial blood flow experiments. The secretarial assistance of Kim Kanitz and Laura Sell and the technical assistance of John R. Liddicoat are greatly appreciated.

\section{REFERENCES}

1. Moncada S, Gryglewski RJ, Bunting S, Vane JR. An enzyme isolated from arteries transforms prostaglandin endoperoxides to an unstable substance that inhibits platelet aggregation. Nature 1976;263:663.

2. Moncada S, Higgs EA, Vane JR. Human arterial and venous tissue generate prostacyclin (prostaglandin $\mathrm{X}$ ), a potent inhibitor of platelet aggregation. Lancet 1977;1:18.

3. Fitzpatrick TM, Alter I, Corey EJ, Ramwell PW, Rose JC, Kot PA. Cardiovascular responses to $\mathrm{PGI}_{2}$ (prostacyclin) in the dog. Circ Res 1978;42:192.

4. Raz A, Isakson PC, Minkes MS, Needleman P. Characterization of a novel metabolic pathway of arachidonate in coronary arteries which generates a potent endogenous vasodilator. $\mathrm{J}$ Biol Chem 1977;252:1123.

5. Ogletree ML, Lefer AM, Smith JB, Nicolaou KC. Studies on the protective effect of prostacyclin in acute myocardial ischemia. Eur J Pharmacol 1979;56:95.

6. Jugdutt BI, Hutchins GM, Bulkley BH, Becker LC. Dissimilar effects of prostacyclin, prostaglandin $E_{1}$, and prostaglandin $E_{2}$ on myocardial infarct size after coronary occlusion in conscious dogs. Circ Res 1981;49:685.

7. Ribeiro LGI, Brandon TA, Hopkins DG, Reduto LA, Taylor A, Miller RR. Prostacyclin in experimental myocardial ischemia: Effects on hemodynamics, regional myocardial blood flow, infarct size and mortality. Am J Cardiol 1981;47:835.

8. Araki H, Lefer AM. Role of prostacyclin in the preservation of ischemic myocardial tissue in the perfused cat heart. Circ Res $1980 ; 47: 757$

9. Lefer AM, Ogletree ML, Smith JB, Silver MJ, Nicolaou KC, Barnette WE, Gasic GP. Prostacyclin: A potentially valuable agent for preserving myocardial tissue in acute myocardial ischemia. Science 1978;200:52.

10. Melin JA, Becker LC. Salvage of ischemic myocardium by prostacyclin during experimental myocardial infarction. $\mathrm{J}$ Am Coll Cardiol 1983;2:279.

11. Lucchesi BR, Romson JL, Jolly SR. Do leukocytes influence infarct size? In Hearse DJ. Yellon DM, editors: Therapeutic approaches to myocardial infarct size limitation. New York: Raven Press, 1984:219.

12. Romson JL, Hook BG, Kunkel SL, Abrams GD, Schork MA, Lucchesi BR. Reduction of the extent of ischemic myocardial injury by neutrophil depletion in the dog. Circulation 1983; 67:1016.

13. Romson JL, Hook BG, Rigot VH, Schork MA, Swanson DP, Lucchesi BR. The effect of ibuprofen on accumulation of indium-111-labelled platelets and leukocytes in experimental myocardial ischemia. Circulation 1982;66:1002.

14. Fantone JC, Kinnes DA. Prostaglandin $E_{1}$, and prostaglandin $I_{2}$ modulation of superoxide production by human neutrophils. Biochem Biophys Res Commun 1983;113:506.

15. Fantone JC, Marasco WA, Elgas LJ, Ward PA. Stimulus specificity of prostaglandin inhibition of rabbit polymorphonuclear leukocyte lysosomal enzyme release and superoxide anion production. Am J Pathol 1984;115:9.

16. Fantone JC, Kunkel SL, Zurier RB. Effects of prostaglandins on in vivo immune and inflammatory reactions. In: Goodwin $\mathrm{J}$, editor. Prostaglandins and immunity. Boston: Martinus Nijhoff Publishers, 1984:123.

17. Werns SW, Shea MJ, Mitsos SE, Dysko RC, Fantone JC, Schork MA, Abrams GD, Pitt B, Lucchesi BR. Reduction of the size of infarction by allopurinol in the ischemic-reperfused canine heart. Circulation 1986;73:518.

18. Sheehan F, Epstein S. Determinants of arrhythmic death due to coronary spasm: Effect of preexisting coronary artery stenosis on the incidence of reperfusion arrhythmias. Circulation 1981; 65:259.

19. Heymann MA, Payne DB, Hoffman IIE, Rudolph AM. Blood flow measurements with radionuclide-labelled particles. Prog Cardiovasc Dis 1977;20:55.

20. Babior BM, Kipnes RS, Curnutte JT. Biological defense mechanisms: The production by leukocytes of superoxide, a potential bactericidal agent. J Clin Invest 1973;52:741.

21. Lundberg C, Arfors K. Polymorphonuclear leukocyte accumula tion in inflammatory dermal sites as measured by ${ }^{51} \mathrm{Cr}$-labelled cells and myeloperoxidase. Inflammation 1983;7:247. 
22. Bradley PP, Priebat DA, Christensen RD, Rothstein G. Measurement of cutaneous inflammation: Estimation of neutrophil content with an enzyme marker. J Invest Dermatol 1982; 78:206.

23. Dunnett $\mathrm{CW}$ : New tables for multiple comparisons with a control. Biometries 1964;20:482.

24. Wallenstein S, Zucker CI, Fleiss JI. Some statistical methods useful in circulation research. Circ Res 1980;47:1.

25. Gobel FL, Nordstrom LA, Nelson RR, Jorgenson CR, Wang Y. The rate-pressure product as an index of myocardial oxygen consumption during exercise in patients with angina pectoris. Circulation 1978;57:549.

26. Jugdutt BI. Effect of $\mathrm{PGE}_{1}, \mathrm{PGE}_{2}$ and $\mathrm{PGI}_{2}$ on ventricular arrhythmias during myocardial infarction in conscious dogs: Relation to infarct size. Prostaglandins Med 1981;7:431.

27. Coker SJ, Parratt JR. Prostacyclin-antiarrhythmic or arrhythmogenic? Comparison of the effects of intravenous and intracoronary prostacyclin and ZK 36374 during coronary artery occlusion and reperfusion in anesthetized greyhounds. J Cardiovasc Pharmacol 1983;5:557.

28. Coker SJ, Parratt JR. Prostacyclin-induced changes in coronary blood flow and oxygen handling in the normal and acutely ischaemic canine myocardium. Basic Res Cardiol 1981;76:457.

29. Einzig S, Sotomora R, Rao GHR, Gerrard JM, Foker JE, White JG. Effect of low dose prostacyclin infusion on blood flow in acutely ischemic canine myocardium. Prostaglandins Med 1980; 5:209.

30. Maroko PR, Kjekshus JK, Sobel BE, Wantanabe T, Covell JW,
Ross J, Braunwald E. Factors influencing infarct size following experimental coronary artery occlusion. Circulation 1971;43:67.

31. Muller KD, Klein H, Schaper W. Changes in myocardial oxygen consumption 45 minutes after experimental coronary artery occlusion do not alter infarct size. Cardiovasc Res 1980;14:710.

32. Kloner RA, Ganote CE, Jennings RB. The "no-reflow" phenomenon after temporary coronary occlusion in the dog. J Clin Invest 1974;54:1496.

33. Nicholson NS, Smith SL, Taite BB, Krueger A, Fuller GC. Evaluation of a stable 5-F prostacyclin analog as an antithrombotic agent in hemodialysis. Drugs Exptl Clin Res 1986;7:371.

34. Hill JH, Ward PA. The phlogistic role of $\mathrm{C} 3$ leukotactic fragments in myocardial infarets in rats. J Exp Med 1971; 133:885.

35. Maroko PR, Carpenter CB, Chiariello M, Fishbein M, Radrany P, Knostman J, Hale S. Reduction by cobra venom factor of myocardial necrosis after coronary artery occlusion. J Clin Invest 1978:61:661.

36. Pinckard RN, O'Rourke RA, Crawford MH, Grover FS, McManus LM, Ghidoni JJ, Stovis SB, Olson MS. Complement localization and mediation of ischemic injury in baboon myocardium. J Clin Invest 1980;66:1050.

37. Kuehl FA, Dougherty HW, Ham EA. Interactions between prostaglandins and leukotrienes. Biochem Pharmacol 1984; 33:1

38. Schumacher WA, Lee EC, Lucchesi BR: Augmentation of streptokinase-induced thrombolysis by heparin and prostacyclin. J Cardiovasc Pharmacol 1985:7:739.

\title{
Hemodynamic effects of BTS 49465, a new long-acting systemic vasodilator drug, in patients with severe congestive heart failure
}

\begin{abstract}
The hemodynamic offects of BTS 49465, a new oral, direct-acting systemic vasodilator drug, were investigated in 10 patients with severe chronic congestive heart fallure. One to 2 hours after the administration of $1.5 \mathrm{mg} / \mathrm{kg}$ orally, BTS 49465 produced significant increases in cardlac index, otroke volume index, and stroke work index $(26 \%, 27 \%$, and $23 \%$, respectlvely, $p<0.01$ to 0.001$)$ and marked decreases in left ventricular flling pressure $(-12.6 \mathrm{~mm} \mathrm{Hg}, 44 \%)$, mean putmonary artery pressure $(-13.2 \mathrm{~mm} \mathrm{Hg}, 31 \%)$, and mean right atrial preseure $(-7.7 \mathrm{~mm}$ $\mathrm{Hg}, 63 \%$ ), all $p<0.001$, without slgnificant changes in heart rate. These hemodynamic responses were accompanled by notable declines in systemlc vascular resistance $(-28 \%, p<0.001)$ and pulmonary arteriolar resistance $(-24 \%, p<0.05)$. These effects persisted throughout the 24-hour period of obeervation. The decline in left ventricular filling pressure in our patients ranged in magnitude from 8 to $21 \mathrm{~mm} \mathrm{Hg}$, and varled linearly and directly with pretreatment values for left ventricular filling preseure $(r=0.69)$. The decresese in systemic vascular resistance ranged in magnifude from $3 \%$ to $40 \%$ and varied linearly and directly with pretreatment values for systemic vascular resiatance $(r=0.85)$. These data indicate that BTS 49465, a new oral, direct-acting vasodilator agent, exerts balanced cardlocirculatory effects in patients with severe chronic heart fallure, which may be sustained with once-dally oral administration. (Am HEART J 1987;113:137.)
\end{abstract}

Paul D. Kessler, M.D., and Milton Packer, M.D.* New York, N.Y.

From the Division of Cardiology, Department of Medicine, Mount Sinai School of Medicine of the City University of New York.

Received for publication Feb. 5, 1986; accepted June 2, 1986.

Reprint requeste: Milton Packer, M.D., Division of Cardiology, Mount Sinai Modical Center, I Gustave Levy Place, New York, NY 10029.
"Dr. Packer is the recipient of a Research Career Development Award (No. K04-HL-01229) from the National Heart, Lung, and Blood Institute, Bethesda, Md. 